\title{
Speculative Hyperinflations in Maximizing Models: Can We Rule Them Out?
}

\section{Citation}

Obstfeld, Maurice, and Kenneth S. Rogoff. 1983. Speculative hyperinflations in maximizing models: Can we rule them out? Journal of Political Economy 91(4): 675-687.

\section{Published Version}

http://www.jstor.org/stable/1831073

\section{Permanent link}

http://nrs.harvard.edu/urn-3:HUL.InstRepos:12491027

\section{Terms of Use}

This article was downloaded from Harvard University's DASH repository, and is made available under the terms and conditions applicable to Other Posted Material, as set forth at http:// nrs.harvard.edu/urn-3:HUL.InstRepos:dash.current.terms-of-use\#LAA

\section{Share Your Story}

The Harvard community has made this article openly available.

Please share how this access benefits you. Submit a story.

\section{Accessibility}




\title{
Speculative Hyperinflations in Maximizing Models: Can We Rule Them Out?
}

\section{Maurice Obstfeld}

Columbia University

\section{Kenneth Rogoff}

Board of Governors, Federal Reserve System

\begin{abstract}
This paper uses an infinite-horizon model based on individual maximizing behavior to study whether explosive price-level paths unrelated to monetary growth-speculative hyperinflations-can be equilibrium paths under rational expectations. In a pure fiat money regime, speculative hyperinflations can be excluded only through severe restrictions on individual preferences; but when the government fractionally backs the currency by guaranteeing a minimal real redemption value for money, speculative hyperinflations are impossible, even if agents are not completely certain that they can redeem their money in any given period. The analysis also confirms that implosive price-level paths and divergent paths for capital asset prices are not equilibria under either monetary regime.
\end{abstract}

Knife-edge stability is a common property of dynamic monetary models assuming perfect foresight or rational expectations. Because expectations are self-fulfilling in these models, unstable price paths are fueled in part by speculative anticipations unrelated to market funda-

We are indebted to William Brock for extremely helpful comments on an earlier version of this paper; to Jo Anna Gray, who directed our attention to the issues analyzed here; to Stanley Fischer; and to two anonymous referees. Obstfeld worked on this paper while a visiting scholar at the International Finance Division of the Federal Reserve Board and acknowledges with thanks the Board's hospitality. He is grateful also for financial support from the National Science Foundation. This paper represents the views of its authors and should not be interpreted as reflecting the views of the Board of Governors of the Federal Reserve System. 
mentals, and for this reason, the unique convergent path (the saddle path) is generally assumed to be the equilibrium path of the system. But while this empirically plausible assumption yields sensible results, the aggregative models in which it is applied are typically not sufficiently detailed to allow one to prove that the saddle path is the unique equilibrium path. Brock $(1974,1975)$ advanced a monetary model based on a complete specification of infinitely lived individuals' preferences and showed how speculative hyperinflations and hyperdeflations might be ruled out. His model and conclusions have provided an important justification for the use of the saddle-path assumption in other macro models with rational expectations. ${ }^{1}$

This paper reexamines those conclusions in a similar maximizing model incorporating productive capital as well as money. Under a pure fiat monetary system, speculative hyperinflationary price-level paths cannot be ruled out as equilibria unless a somewhat unintuitive restriction is imposed on agents' utility functions. An identical restriction is needed to eliminate hyperinflations in Brock's (1974, 1975) model, and a similar one is needed in other models of pure fiat money. ${ }^{2}$ We argue that this restriction is economically unreasonable and show it implies that agents would have infinitely negative utility if they held zero real balances.

Speculative paths can be eliminated without such restrictions on preferences provided the government fractionally backs the currency by standing ready to redeem each dollar for a small amount of capital. Agents need not have complete faith in the government's promise; even a small probability that the government will redeem dollars for capital turns out to be sufficient to preclude speculative hyperinflations. ${ }^{3}$

\footnotetext{
'See, e.g., Lucas (1975), Kouri (1976), and Fischer (1979). Flood and (Garber (1980) have attempted to provide further justification for the saddle-path assumption by testing it empirically on data from the German hyperinflation.

${ }^{2}$ Brock (1978) demonstrates that this restriction is needed to preclude explosive (but not implosive) price paths in a continuous-time version of his discrete-time model. In this paper we show that the restriction is needed in the discrete-time case as well. Brock and Scheinkman (1980) prove that a similar condition eliminates hyperinflationary equilibria in certain overlapping-generations models of fiat money. Scheinkman (1980) does the same in a variant of the Clower (1967) cash-in-advance model, as does Gray (1982) in a model where money is assumed to reduce transaction costs.

${ }^{3}$ Brock (1982b) shows that the government can prevent speculative hyperinflations by introducing an arbitrarily small tax-financed real subsidy proportional to nominal money holdings. He first conjectured the result that even a small probability of government intervention eliminates speculative paths. Wallace (1981), in a nonstochastic overlapping-generations model, advances a government intervention scheme similar to the one studied in this paper; but in his setup money is backed by the perishable consumption good rather than by a durable asset.
} 


\section{The Model}

In this section we study the pricing of pure fiat money and productive capital in an economy of infinitely lived, utility-maximizing agents with perfect foresight. As in Brock (1974, 1975), a demand for money arises through the assumption that an agent's direct utility depends on his stock of real balances as well as his consumption level. ${ }^{4}$

Each of the identical agents lives forever and maximizes the present discounted value of his utility stream,

$$
W=\sum_{t=0}^{\infty} \beta^{t}\left[u\left(c_{t}\right)+v\left(m_{t}\right)\right], \quad \beta<1,
$$

where $c_{t}$ denotes consumption and $m_{t}$ is the ratio of nominal money holdings $M_{t}$ to the price level $P_{t}$. The functions $u(\cdot)$ and $v(\cdot)$ are increasing in their respective arguments, strictly concave, differentiable on the open interval $(0, \infty)$, and they obey the Inada conditions: $\lim _{c \rightarrow 0} u^{\prime}(c)=\infty, \lim _{\leftrightarrow \rightarrow \infty} u^{\prime}(c)=0, \lim _{m \rightarrow 0} v^{\prime}(m)=\infty, \lim _{m \rightarrow \infty} v^{\prime}(m)=0$.

Individuals may hold two assets, fiat money and nondepreciating capital. A unit of capital yields a fixed physical return of $r$ units of the perishable consumption good at the end of each period. ${ }^{5}$ At the beginning of each period, a typical agent receives from the government a transfer of $h_{t}$ units of the consumption good. The individual's flow budget constraint is therefore

$$
A_{t}-A_{t-1}=P_{t} r k_{t-1}+\left(Q_{t}-Q_{t-1}\right) k_{t-1}+P_{t} h_{t}-P_{t} c_{t} .
$$

In (2), $A_{t}$ denotes nominal assets in period $t$; $k_{t}$ denotes physical capital holdings; $Q_{t}$ is the money price of capital; and $M_{0}$ and $k_{0}$ are given. The wealth constraint is

$$
A_{t}=M_{t}+Q_{t} k_{t}
$$

\footnotetext{
${ }^{4}$ The model of this section is a discrete-time version of the model in Obstfeld (1982). Like Brock, we focus on the case of a separable utility function. If instead real money balances and the consumption good are substitutes, there may be multiple convergent equilibria, even if both goods are everywhere normal (see Obstfeld 1982). The present paper ignores the possibility that there may exist more than one convergent equilibrium path. It is concerned only with the possibility that an economy possessing a single convergent equilibrium path may also possess divergent equilibrium paths. Calvo (1978, 1979) and Taylor (1977), the latter in the context of a descriptive model, describe economies with multiple convergent rational expectations equilibria.

"A unit of capital may thus be thought of as a Lucas (1978) "tree" with a nonstochastic yield.
} 
The necessary first-order (Euler) conditions for the individual's problem are ${ }^{6}$

$$
\begin{gathered}
u^{\prime}\left(c_{t}\right) / P_{t}=\left[v^{\prime}\left(M_{t} / P_{t}\right) / P_{t}\right]+\left[\beta u^{\prime}\left(c_{t+1}\right) / P_{t+1}\right], \\
u^{\prime}\left(c_{t}\right) q_{t}=\beta u^{\prime}\left(c_{t+1}\right)\left(q_{t+1}+r\right),
\end{gathered}
$$

where $q_{t} \equiv Q_{t} / P_{t}$ is the real price of capital. Condition (4) states that along an optimal path, the utility cost of obtaining $\$ 1.00$ at time $t$ must equal the utility gain from holding that dollar for a period and converting it back into consumption at time $t+1$. Similarly, condition (5) states that the individual cannot gain from buying an extra unit of capital at time $t$ and converting it back into consumption at time $t+1$.

Markets clear at the beginning of each period. The total supply of capital in the economy, $k$, is fixed and is divided between the portion held by the government, $k^{g}$, and the portion held by the public, $k-k^{g}$. There is no government consumption, and the money supply is constant at level $M$. The earnings $r k^{g}$ on the government's capital holdings are fully rebated to the public in the form of the transfers $h_{t}$.

In equilibrium, the private demand for consumption during period $t, c_{t}$, must equal the economy's output $y \equiv r k$. Furthermore, the demand for nominal balances, $M_{t}$, must equal the supply $M$ for all $t$. By combining the market-clearing conditions with the necessary Euler conditions (4) and (5), we obtain two first-order difference equations in $m$ and $q$ :

$$
\begin{aligned}
\beta u^{\prime}(y) m_{t+1} & =m_{t}\left[u^{\prime}(y)-v^{\prime}\left(m_{t}\right)\right], \\
q_{t+1} & =\left(q_{t} / \beta\right)-r .
\end{aligned}
$$

Note that equation (6) is identical to the equation describing the dynamics of Brock's $(1974,1975)$ monetary model. The dynamics of real money balances $m$ and the real price of capital $q$ are independent here for two reasons. First, the capital stock is given and cannot be augmented through saving. Second, the instantaneous utility function is separable.

While there are many Euler paths for $m$ and $q$-paths which satisfy (6) and (7) - not all are equilibrium paths. We now discuss conditions under which all but one of these "candidate" equilibria can be ruled out.

${ }^{6}$ The first-order conditions (4) and (5) are obtained by maximizing the Lagrangian

$$
\begin{gathered}
\sum_{t=0}^{\infty} \beta^{t}\left\{\left[u\left(c_{t}\right)+v\left(M_{t} / P_{t}\right)\right]+\gamma_{t}\left(A_{t}-M_{t}-Q_{t} k_{t}\right)\right. \\
\left.-\lambda_{t}\left[A_{t}-A_{t-1}-\left(P_{t} r+Q_{t}-Q_{t-1}\right) k_{t-1}-P_{t} h_{t}+P_{t} c_{t}\right]\right\}
\end{gathered}
$$

with respect to $c_{t}, A_{t}, M_{t}$, and $k_{t}$ and then eliminating the multipliers $\lambda_{t}, \lambda_{t+1}$, and $\gamma_{t}$ from the resulting expressions. 


\section{The Transversality and Infeasibility Conditions}

This section begins by showing that the unique path for the real price of capital consistent with economy-wide equilibrium is the steady-state path, $q_{t}=\bar{q}=\beta r /(1-\beta)$ for all $t$. A condition on agents' utility functions under which all but a single, constant, nominal price-level path can be ruled out is then established and interpreted.

To rule out paths for $q$ originating below $\bar{q}$, rewrite the Euler-path equation (7) in the form

$$
q_{t+1}-\bar{q}=(1 / \beta)\left(q_{t}-\bar{q}\right)
$$

and observe that if $q_{0}<\bar{q}$, $q_{t}$ must become negative in finite time. Such implosive $q$ paths are infeasible under the assumption that agents can freely dispose of both capital and money. Explosive $q$ paths-those originating above $\bar{q}$ - can be excluded by the following transversality argument. ${ }^{7}$ Applying successive substitutions to (5), one obtains the necessary condition

$$
u^{\prime}\left(c_{t}\right) q_{t}=\sum_{s=1}^{T} \beta^{s} u^{\prime}\left(c_{t+s}\right) r+\beta^{T} u^{\prime}\left(c_{t+T}\right) q_{t+T} .
$$

Equation (9) implies that, along an optimal path, the utility gain from converting a unit of capital into consumption at time $t$ and repurchasing the capital at time $t+T$ must equal the utility value of the interest earnings forgone in the interim. But it is also necessary for optimality that the utility gain from consuming a unit of capital at time $t, u^{\prime}\left(c_{t}\right) q_{t}$, not exceed the utility value of the interest earnings forgone if the capital is never repurchased, $\Sigma_{s=1}^{x} \beta^{\prime} u^{\prime}\left(c_{t+s}\right) r$. As (9) shows, the latter condition can hold only if $\lim _{T \rightarrow \infty} \beta^{T} u^{\prime}\left(c_{t+T}\right) q_{t+T}=0$. When $q$ originates above $\bar{q}$, the foregoing limit is, by $(8)$, strictly positive. Faced with a $q$ path that violates the transversality condition in this manner, all individuals would wish to reduce their capital holdings permanently. Since this is not possible in the aggregate, explosive $q$ paths are not equilibrium paths. Thus $q_{t}=\bar{q}$ for all $t$ is necessary for equilibrium. ${ }^{\gamma}$

Having established that divergent speculative paths cannot arise on the nonmonetary side of our model, we now study conditions under

\footnotetext{
${ }^{7}$ The intuitive interpretation of the transversality condition presented below draws heavily on Gray (1982). The necessity of transversality conditions is discussed by Benveniste and Scheinkman (1982) and by Weitzman (1973). Brock (1982a) applies their results in a stochastic model of real capital asset pricing.

${ }^{8}$ Strictly speaking, the transversality condition for the individual's problem is $\lim _{T \rightarrow x}$ $\beta^{T} u^{\prime}\left(c_{t+T}\right) q_{t+T} k_{t+T}=0$ if the individual can reduce his capital holdings to zero but not below zero (see Gray and Salant 1981). Because we have assumed here that all individuals are identical, however, each individual will hold the same positive quantity of capital along an equilibrium path for the economy.
} 
680

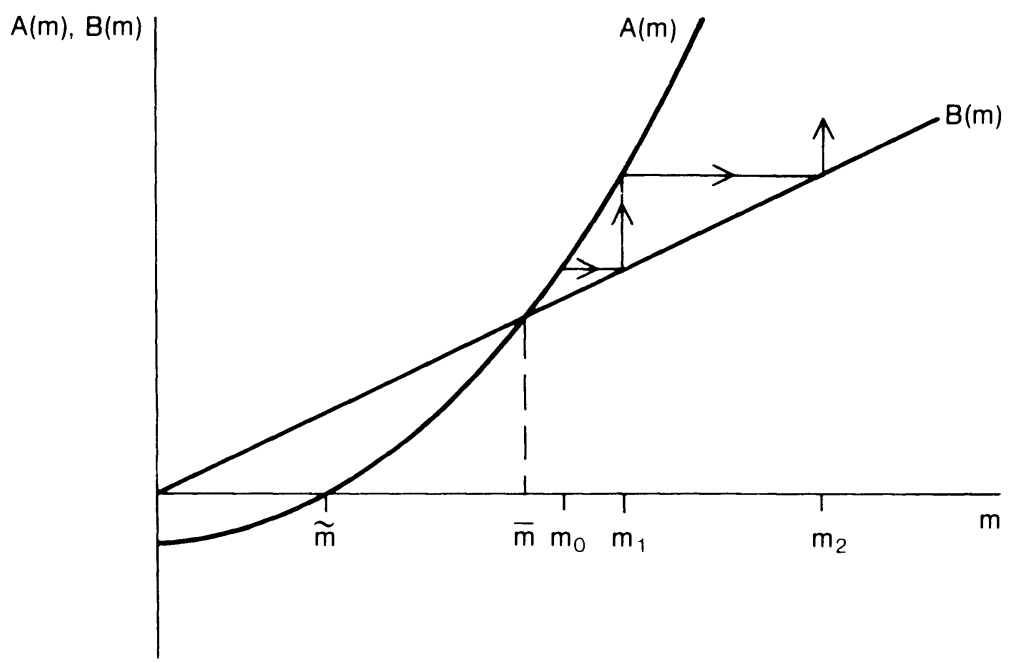

Fig. 1. $-\lim _{m \rightarrow 0)} m v^{\prime}(m)>0$

which the path of the price level is unique. For this purpose it is convenient to employ the diagrammatic technique introduced by Brock $(1974,1975)$. Define $A(m) \equiv m\left[u^{\prime}(y)-v^{\prime}(m)\right]$ and $B(m)=$ $\beta u^{\prime}(y) m$. Euler-path equation (6) may then be written $A\left(m_{t}\right)=$ $B\left(m_{t+1}\right)$. As shown in figures 1 and 2, the $B(m)$ schedule is a straight line of slope $\beta u^{\prime}(y)$ emanating from the origin. By the Inada condition $\lim _{m \rightarrow 0} z^{\prime}(m)=\infty$, the $A(m)$ schedule intersects the horizontal axis at

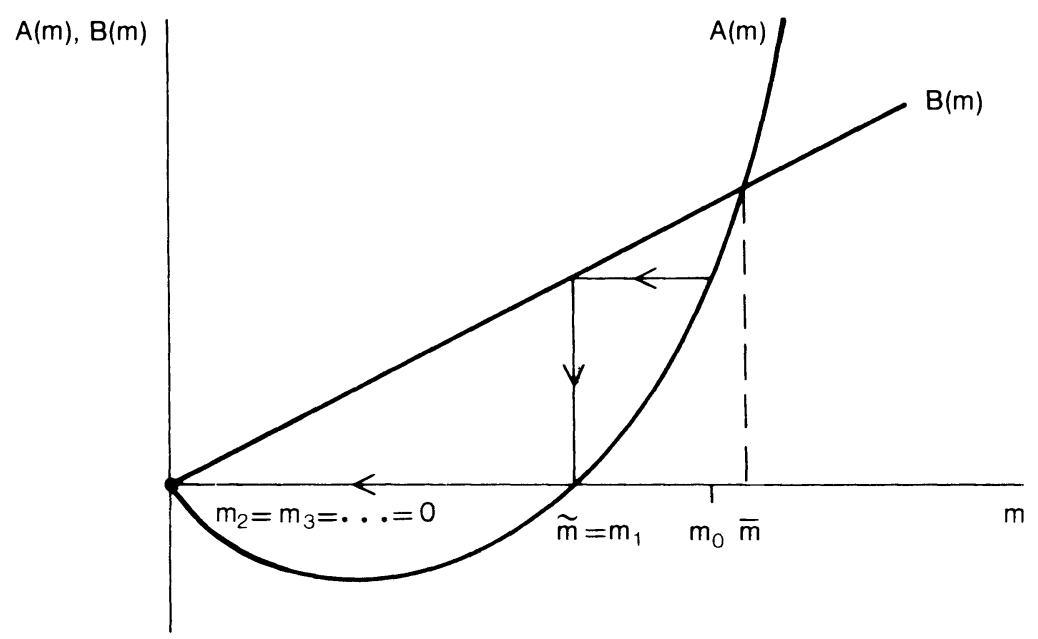

FIG. 2. $-\lim _{m \rightarrow 0} m v^{\prime}(m)=0$ 
$\tilde{m}>0$, where $r^{\prime}(\tilde{m})=u^{\prime}(y)$. Because $r^{\prime}(\cdot)$ is strictly concave, $A(m)$ is positive and increasing for $m>\tilde{m}$, and $A(m)$ is negative for $0<m<\tilde{m}$. Since $\beta<1, A(m)$ and $B(m)$ intersect at some $\bar{m}>\tilde{m}$. This positive steady-state level of real balances $\bar{m}$ can be shown to be unique." Whether the two schedules also intersect at $m=0$ depends on the shape of $\imath^{\prime}(\cdot)$ for $m<\tilde{m}$. If $\lim _{m \rightarrow 0} A(m)=-\lim _{m \rightarrow 0} m \eta^{\prime}(m)<0$, we have the configuration of figure 1 . If instead $\lim _{m \rightarrow 0} m v^{\prime}(m)=0$, we have that of figure 2.10

In figure 1 we illustrate a time path of real balances $\left\{m_{0}, m_{1}, m_{2}, \ldots\right\}$ originating at $m_{0}>\bar{m}$. Such paths are explosive and may be ruled out because they violate a necessary transversality condition. ${ }^{11}$ Iterating equation (4) forward, we obtain its multiperiod analogue,

$$
u^{\prime}\left(c_{t}\right) / P_{t}=\sum_{s=0}^{T-1}\left[\beta^{\prime} \gamma^{\prime}\left(m_{t+s}\right) / P_{t+s}\right]+\left[\beta^{T} u^{\prime}\left(c_{t+T}\right) / P_{t+T}\right] .
$$

By taking the limit of $(10)$ as $T \rightarrow \infty$, one sees the necessity of the transversality condition $\lim _{T \rightarrow \infty}\left[\beta^{T} u^{\prime}\left(c_{t+T}\right) / P_{t+T}\right]=0$. This condition ensures that an individual cannot raise his welfare by permanently reducing his nominal balances by $\$ 1.00$. (See also Brock 1975 .) While explosive real balance paths originating above $\bar{m}$ violate the transversality condition, the steady-state Euler path, $m_{t}=\bar{m}$ for all $t$, does not. Because the steady-state path is also feasible, it is therefore an equilibrium path.

Consider next paths originating at $m_{0}<\bar{m}$. Along these speculative hyperinflationary paths, real balances decline over time even though the nominal money stock is constant. We now argue that all such paths may be ruled out as equilibria if, and only if, the following infeasibility condition holds:

$$
\lim _{m \rightarrow 0} m v^{\prime}(m)>0 .
$$

The argument is as follows. First, return to figure 1, which is drawn on the assumption that (11) does hold. By inspection, any solution to (6) initiated by $m_{0}<\bar{m}$ requires that $m_{t}$ eventually become negative. These paths are infeasible and may therefore be excluded from the class of possible equilibrium paths. It follows that when (11) is assumed, the steady-state path is the unique equilibrium path.

When $m v^{\prime}(m) \rightarrow 0$ as $m \rightarrow 0$, as in figure 2, most Euler paths starting

\footnotetext{
${ }^{9}$ Clearly, $B(\tilde{m})>A(\tilde{m})=0$. Because $v^{\prime \prime}(m)<0$ and $\lim _{m \rightarrow \infty} v^{\prime}(m)=0, A(m)$ and $B(m)$ intersect at least once at some $\bar{m}>\tilde{m}$. Uniqueness of $\bar{m}$ is an immediate consequence of the strict concavity of $v(\cdot)$.

${ }^{10}$ If $-\lim _{m \rightarrow 0} m v^{\prime}(m)=-\infty$, e.g., when $v(m)=m^{1-R} /(1-R)$ and $R>1$, the $A(m)$ schedule cuts the vertical axis only at $-\infty$.

${ }^{11}$ As $m_{t} \rightarrow \infty$, Euler-path eq. (6) becomes, approximately, $m_{t+1}=m_{t} / \beta$. Eventually, therefore, the price level falls at rate $\beta$.
} 
to the left of $\bar{m}$ are again infeasible. However, Euler paths which pass through $\tilde{m}$, such as the one depicted in figure 2, are not infeasible: While the price level becomes and remains infinite after a finite number of periods, ${ }^{12}$ real balances need not become negative to generate a path satisfying $(6)$.

To show that these speculative hyperinflationary Euler paths are equilibrium paths, we must answer two questions. First, why do agents hold positive real balances at any time if they expect the price level to become and remain infinite after a finite number of periods? The reason is that $\tilde{m}$, the equilibrium real money stock in the period before the price level becomes infinite, satisfies $v^{\prime}(\tilde{m})=u^{\prime}(y)$. Thus, agents are content to hold $\tilde{m}>0$ without attempting to increase consumption above $y$. The utility gained by consuming a dollar just equals that lost through the concomitant reduction in real balances. The individual is not concerned that his dollars will be worthless next period. ${ }^{13}$

The second question relates to the assumption $v^{\prime}(0)=\infty$. Since the marginal utility of money grows without bound as $m \rightarrow 0$, will it not pay for the individual at some point to "consume a little less and harvest a large marginal utility from money services"? ${ }^{14}$ To answer this, we consider the transversality argument: Suppose that an individual permanently adds a dollar to his money holdings at some time $t$ before the price level jumps to infinity. If the price level becomes infinite at time $t+L$, then $v^{\prime}\left(m_{t+L-1}\right)=v^{\prime}(\tilde{m})=u^{\prime}(y)$; and by setting $T=L-1$ in (10) and assuming equilibrium we obtain

$$
u^{\prime}(y) / P_{t}=\sum_{s=0}^{L-1}\left[\beta^{s} v^{\prime}\left(m_{t+s}\right) / P_{t+s}\right]
$$

The gain from holding an extra dollar forever when it is known that money will lose its purchasing power at time $t+L$ is given by

$$
\sum_{s=0}^{L,-1}\left[\beta^{s} v^{\prime}\left(M / P_{t+s}\right) / P_{t+s}\right]+\lim _{P \rightarrow \infty}\left\{\sum_{s=L}^{\infty}\left[\beta^{s} v^{\prime}(M / P) / P\right]\right\} \text {. }
$$

\footnotetext{
${ }^{12}$ Strictly speaking, the derivation of first-order conditions in the previous section assumed finite prices. We therefore proceed from first principles in arguing below that paths along which $m \rightarrow 0$ in finite time can be equilibrium paths. It is worth noting that when $\lim _{m \rightarrow 0} v^{\prime}(m)<u^{\prime}(y)$ (contrary to the assumption in the text), the $A(m)$ schedule does not intersect the horizontal axis but is always above it. In this case, any path originating to the left of $\bar{m}$ is an equilibrium path (provided $\bar{m}>0$ ). Along such paths, the price level approaches infinity asymptotically.

${ }_{13}$ The possibility of speculative hyperinflationary paths in this pure fiat money model does not disappear when agents' lives are finite. If $\lim _{m \rightarrow()} m v^{\prime}(m)=0$ and agents choose an initial real balance level that leads them to hold real balances $\tilde{m}$ at some point before their lives end, the price level will still become infinite in the next period.

${ }^{14}$ Brock (1975, p. 138) uses this argument to rule out hyperinflationary equilibrium paths.
} 
When $\lim _{m \rightarrow 0} m v^{\prime}(m)=0$, expression (13) equals the right-hand side of (12), and so the gain from holding an additional dollar forever just equals the utility forgone to obtain the dollar at time $t$.

Of course, if $\lim _{m \rightarrow 0} m v^{\prime}(m)>0$, then the limit in (13) is positive and (13) therefore exceeds the right-hand side of (12). In this case, each individual would try to permanently increase his nominal money holdings along implosive real balance paths, but he would do so because the infeasibility condition (11) implies that money has intrinsic value for him even when the price level is infinite. Evidently, the infeasibility condition (11), which is necessary for price-level uniqueness in this model, places a very severe restriction on the utility function $v(\cdot)$. The severity of this restriction is illustrated by the following:

THEOREM: If $\lim _{m \rightarrow 0} m v^{\prime}(m)>0$, then $\lim _{m \rightarrow 0} v(m)=-\infty$.

Proof: Because $v^{\prime}(m)>0, \lim _{m \rightarrow 0} v(m) \equiv a$ exists but may equal $-\infty$. Suppose (contrary to the assertion of the theorem) that $a$ is finite. If $\lim _{m \rightarrow 0} m v^{\prime}(m)>0$, there exists a positive number $b$ and a level of real balances $m^{*}$ such that $m v^{\prime}(m) \geqslant b$ for all $m<m^{*}$. The strict concavity of $v(\cdot)$ implies that, for $m<m^{*}, v(m)-a>m v^{\prime}(m) \geqslant b$. But if $a$ is finite, $m$ can be chosen small enough so that $m<m^{*}$ and $v(m)-$ $a<b$; and this contradicts the foregoing string of inequalities. Therefore, $a=\lim _{m \rightarrow 0} v(m)=-\infty$.

The theorem shows how important money must be if speculative hyperinflationary equilibria are to be excluded under a pure fiat monetary system. It must be true that if an agent is deprived of his real balances, no finite increase in his endowment of the consumption good can restore him to his previous utility level. ${ }^{15}$ This requirement seems inconsistent with the view that the utility-of-money function $v(\cdot)$ captures money's role in reducing the frictions that would characterize a complex barter economy. ${ }^{16}$

${ }^{15}$ Note, however, that the converse of the theorem is not true. Thus, the assumption $\lim _{m \rightarrow 0} v(m)=-\infty$ is necessary, but not sufficient, to preclude speculative hyperinflationary equilibria. A concave function $v(\cdot)$ such that $v(m)=[\log (m)]^{1 / 3}$ for $m$ $\leqslant \exp (-2 / 3)$ has the property that $\lim _{m \rightarrow 0} v(m)=-\infty$ but also satisfies $\lim _{m \rightarrow 0} m v^{\prime}(m)$ $=0$. Note, however, that if $v^{\prime}(0)=-\infty$ and $P \rightarrow \infty$ in finite time, the individual's maximization problem has no solution. The interpretation of hyperinflationary (but feasible) Euler paths becomes problematic in this case.

${ }^{16}$ Brock (1974) contains a brief discussion of the money-in-the-utility-function approach. He shows that the latter is equivalent to assuming that each agent derives utility from consumption and leisure, where leisure is an increasing function of real balances because money saves transactions time. However, that story does not provide a plausible rationalization for the infeasibility condition (11). While it may be reasonable to assume that utility is infinitely negative when leisure is zero, it is not reasonable to assume that an agent who does not hold money will have no leisure time. Gray (1982) specifies a somewhat different role for money, one in which real balances reduce the output cost of transactions rather than their cost in terms of leisure. The condition necessary for uniqueness of equilibrium in Gray's model is formally identical to (11), 


\section{The Uniqueness of Equilibrium under Fractional Backing}

The previous sections have assumed a pure fiat monetary system and ignored the possibility that the government might back money by standing ready to redeem each dollar for a specified amount of some real asset. This section shows that government backing can eliminate speculative hyperinflationary equilibria, even if that backing is uncertain and arbitrarily small.

Consider initially a monetary regime under which the government promises to redeem each dollar bill for $\epsilon$ units of capital but does not offer to sell money for capital. ${ }^{17}$ Because the price of capital in terms of consumption must equal its steady-state value $\bar{q}$ in equilibrium, the government's promise in effect guarantees that $\$ 1.00$ can always buy at least $\epsilon \bar{q}$ units of consumption. It is assumed that $\epsilon$ is chosen to be sufficiently small that $1 / \epsilon \bar{q}>\bar{P}$, where $\bar{P}$ is the steady-state price level. The official backing is thus fractional in the sense that the real output obtained by returning $\$ 1.00$ to the government is less than what could be obtained by selling the dollar on the market in steady-state equilibrium.

Feasibility of the government's policy requires that the government have access to sufficient reserves of capital to purchase the entire money stock $M$ at the support price $\epsilon$. Otherwise, speculative inflationary paths involving a sudden run on the government's reserves cannot be excluded. ${ }^{18}$ The government's reserve stock naturally includes at least the physical capital it owns $\left(k^{g}\right) .{ }^{19}$

To see how a feasible fractional backing arrangement can eliminate speculative hyperinflationary paths, it is convenient to assume that $\epsilon$ is chosen sufficiently small that $\overline{\bar{P}} \equiv 1 / \epsilon \bar{q}>\tilde{P}$, that is, so that $u^{\prime}(y)-$ $r^{\prime}(M / \overline{\bar{P}})<0 .{ }^{20}$ With fractional backing the aggregate nominal money stock is endogenous, for it may fall at a point in time should agents

except that a transactions function replaces the utility-of-money function. The theorem of this section can be used to prove that Gray's uniqueness condition holds only when transaction costs eat up more than 100 percent of output in the absence of money. It is therefore impossible to rule out speculative hyperinflations when the demand for pure fiat money arises from Gray's transactions technology.

${ }^{17}$ The asset used to back the currency may be thought of as "gold" that appreciates in real terms at a fixed exogenous rate $r$. We analyze capital backing rather than gold backing here in order to avoid modeling the role of gold in consumption and/or production. But our results would clearly carry over to a model in which currency is redeemable in terms of gold.

${ }^{18}$ Salant (1983) studies how runs can occur under government price-fixing schemes and provides references to related literature. Note that while runs may occur if backing is insufficient, they do not occur of necessity in the present context.

${ }^{19}$ The government's potential reserves are larger if it can issue bonds that are perfect substitutes for capital, financing interest payments through taxation.

${ }^{20}$ This assumption is made solely for expository purposes; higher values of $\epsilon$ will prevent speculative hyperinflations provided the government has the resources to buy back the money supply at the quoted price. 
decide to trade in their money. An equilibrium price-level path for real balances must still be governed by (4). Equation (14) below is the same as (4) except that we have substituted the equilibrium condition $c_{t}=c_{t+1}=y$ :

$$
\left[u^{\prime}(y)-v^{\prime}\left(M_{t} / P_{t}\right)\right] / P_{t}=\beta u^{\prime}(y) / P_{t+1} .
$$

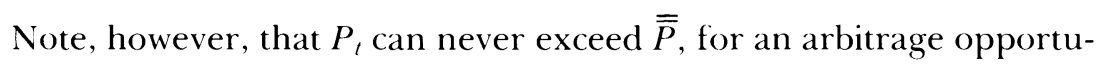
nity inconsistent with equilibrium would exist if the nominal market price of capital, $P_{l} \bar{q}$, were to exceed the government's selling price, $\overline{\bar{P}} \bar{q}=1 / \epsilon$. Obviously, no money is ever turned in for capital while $P_{1}<$ $\overline{\bar{P}}$. The steady-state path of the pure fiat money economy, with $M_{t}=$ $M$ and $P_{t}=\bar{P}$ for all $t$, remains an equilibrium path under our new assumptions. But it is easy to see that speculative hyperinflationary paths can now be ruled out even if $\lim _{m \rightarrow 0} m v^{\prime}(m)=0$. Suppose that $\left\{P_{t}\right\}$ is an equilibrium path with $P_{0}>\bar{P}$. Let $P_{T}=\max \left\{P_{t} \mid P_{t}<\overline{\bar{P}}\right\}$. By (14), $P_{T}$ must be below $\tilde{P}$, so that $u^{\prime}(y)-v^{\prime}\left(M / P_{T}\right)>0$, while $P_{T+1}$ must exceed $P_{T}$ and therefore equal $\bar{P}$. But there is no $M_{T+1} \leqslant$ $M$ such that $u^{\prime}(y)-v^{\prime}\left(M_{T+1} / \overline{\bar{P}}\right) \geqslant 0$. Thus, there is no price level $P_{T+2}$ satisfying (14) and $\left\{P_{t}\right\}$ is not an equilibrium path.

The government's intervention need not be certain as we have assumed. Even the possibility of intervention suffices to rule out speculative paths. Assume now that in any period the government sells capital for money at nominal price $1 / \epsilon$ with a probability $\pi$ that does not depend on what has occurred in previous periods. Let $P_{0}>\bar{P}$ be the initial price level of some Euler path. Agents now maximize expected utility, but as long as $P$ lies below $\overline{\bar{P}}$, the path of the economy does not depend on the realization of the government's coin flip. Again, let $P_{T}$ be the highest price level on that path below $\overline{\bar{P}}$. In period $T+1$, the price level equals $\bar{P}$ (with probability $\pi$ ) or $P_{T+1} \geqslant \bar{P}$ (with probability $1-\pi)$; thus $\left[u^{\prime}(y)-v^{\prime}\left(M / P_{T}\right)\right] / P_{T}=\beta u^{\prime}(y)\left\{(\pi / \overline{\bar{P}})+\left[(1-\pi) / P_{T+1}\right]\right\}$. Regardless of the outcome, $u^{\prime}(y)-v^{\prime}\left(m_{T+1}\right)<0$, so that there is no distribution of the price level for period $T+2$ consistent with equilibrium.

The backing schemes we have been considering preclude speculative hyperinflations even though the government need never actually execute the exchange it offers to make. The government is thus able to guarantee that the economy follows the steady-state path. Because consumption is the same along all paths but real balances are higher on the steady-state path than on any speculative hyperinflationary path, a backing scheme may also guarantee that all individuals are better off. ${ }^{21}$

\footnotetext{
${ }^{21}$ Strictly speaking, the analysis presented here does not permit us to conclude that a system of fractional backing is definitely Pareto superior to a pure fiat money regime
} 


\section{Conclusions}

This paper has used an infinite-horizon monetary model based on individual maximizing behavior to study whether divergent speculative price-level paths can be equilibrium paths under rational expectations. The model confirms the standard results that explosive and implosive paths for capital asset prices and implosive price-level paths are inconsistent with equilibrium. Under a regime of pure fiat money, however, explosive price-level paths-speculative hyperinflationscan be ruled out only when severe restrictions are placed on individual preferences. In particular, agents must have infinitely negative utility when their real balances are zero. The theorem yielding this conclusion can be applied to similarly interpret the conditions needed to preclude speculative hyperinflations in other models of pure fiat money.

If the government fractionally backs the currency by guaranteeing a minimal real redemption value for money, the problem of speculative hyperinflation disappears. ${ }^{22}$ Even though the government need never exercise its redemption guarantee, hyperinflationary equilibria, in which the welfare of all is lower than in the steady-state equilibrium, are eliminated. As Brock (1982b) has conjectured, speculative hyperinflations can be ruled out even if agents are not completely certain that they can redeem their money in any given period.

\section{References}

Benveniste, L. M., and Scheinkman, José A. "Duality Theory for Dynamic Optimization Models of Economics: The Continuous Time Case." J. Econ. Theory 27 (June 1982): 1-19.

$\rightarrow$ Brock, William A. "Money and Growth: The Case of Long Run Perfect Foresight." Internat. Econ. Rev. 15 (October 1974): 750-77.

$\longrightarrow$ "A Simple Perfect Foresight Monetary Model." J. Monetary Econ. 1 (April 1975): 133-50.

- . "A Note on Hyper-Inflationary Equilibria in Long Run Perfect

Foresight Monetary Models: A Correction." Mimeographed. Chicago: Univ. Chicago, Dept. Econ., 1978.

$\overline{\text { because }(a)}$ the steady-state path is a possibility under a pure fiat money regime and $(b)$ there may be some administrative costs associated with a system of fractional backing. (Wallace [1981] has emphasized these points.)

${ }^{22}$ It should be apparent from the analysis presented here that if the paper on which pure fiat money is printed has some small intrinsic value, then speculative hyperinflations can be ruled out without a government backing guarantee. While it is clear that paper money can be burned or used as wallpaper, we still regard it as an empirical question whether the scattered bits of paper would have a nonzero exchange value in a nonmonetary equilibrium. The costs associated with gathering up enough paper money to heat a building or wallpaper a room might make it unprofitable to use paper money for these purposes. 
. "Asset Prices in a Production Economy." In The Economics of Information and Uncertainty, edited by John J. McCall. Chicago: Univ. Chicago Press (for Nat. Bur. Econ. Res.), 1982. (a)

- "Speculative Hyperinflations in Maximizing Models: Corrigendum and Clarification." Mimeographed. Madison: Univ. Wisconsin, Dept. Econ., 1982. (b)

Brock, William A., and Scheinkman, José A. "Some Remarks on Monetary Policy in an Overlapping Generations Model." In Models of Monetary Economies, edited by John Kareken and Neil Wallace. Minneapolis: Federal Reserve Bank of Minneapolis, 1980.

Calvo, Guillermo A. "On the Indeterminacy of Interest Rates and Wages with Perfect Foresight.” J. Econ. Theory 19 (December 1978): 321-37.

- "On Models of Money and Perfect Foresight." Internat. Econ. Rev. 20 (February 1979): 83-103.

Clower, Robert W. "A Reconsideration of the Microfoundations of Monetary Theory." Western Econ. J. 6 (December 1967): 1-8.

$\rightarrow$ Fischer, Stanley. "Capital Accumulation on the Transition Path in a Monetary Optimizing Model.” Econometrica 47 (November 1979): 1433-39.

$\rightarrow$ Flood, Robert P., and Garber, Peter M. "Market Fundamentals versus PriceLevel Bubbles: The First Tests.” J.P.E. 88 (August 1980): 745-70.

Gray, Jo Anna. "Dynamic Instability in Rational Expectations Models: An Attempt to Clarify." International Finance Discussion Papers no. 197. Washington: Board of Governors, Federal Reserve System, January 1982.

Gray, Jo Anna, and Salant, Stephen W. "Transversality Conditions in Infinite Horizon Models." International Finance Discussion Papers no. 172. Washington: Board of Governors, Federal Reserve System, January 1981.

Kouri, Pentti J. K. "The Exchange Rate and the Balance of Payments in the Short Run and in the Long Run: A Monetary Approach." Scandinavian J. Econ. 78 (May 1976): 280-304.

$\rightarrow$ Lucas, Robert E., Jr. "An Equilibrium Model of the Business Cycle." J.P.E. 83 (December 1975): 1113-44.

- "Asset Prices in an Exchange Economy." Econometrica 46 (November 1978): 1429-45.

Obstfeld, Maurice. "Multiple Stable Equilibria in an Optimizing PerfectForesight Model." Mimeographed. New York: Columbia Univ., Dept. Econ., 1982.

$\rightarrow$ Salant, Stephen W. "The Vulnerability of Price Stabilization Schemes to Speculative Attack." J.P.E. 91 (February 1983): 1-38.

Scheinkman, José A. "Discussion." In Models of Monetary Economies, edited by John Kareken and Neil Wallace. Minneapolis: Federal Reserve Bank of Minneapolis, 1980.

Taylor, John B. "Conditions for Unique Solutions in Stochastic Macroeconomic Models with Rational Expectations." Econometrica 45 (September 1977): 1377-85.

Wallace, Neil. "A Hybrid Fiat-Commodity Monetary System.” J. Econ. Theory 25 (December 1981): 421-30.

$\rightarrow$ Weitzman, Martin L. "Duality Theory for Infinite Horizon Convex Models." Management Sci. 19 (March 1973): 783-89. 